\title{
Vírus detectados em plantas ornamentais no período 2004 a $2008^{(1)}$
}

\author{
MARIA AMÉLIA VAZ ALEXANDRE(2), LÍGIA MARIA LEMBO DUARTE(2), \\ ELIANA BORGES RIVAS ${ }^{(2)}$ e SILVIA REGINA GALLETI(3)
}

\begin{abstract}
RESUMO
A produção comercial de flores e plantas ornamentais tornou-se uma atividade economicamente importante no Brasil e vem aumentando gradativamente, visando abastecer o mercado interno e externo com consumidores cada vez mais exigentes. Problemas relacionados ao cultivo e manejo de espécies recentemente introduzidas, bem como os relativos à sanidade das plantas podem constituir um entrave à floricultura nacional. Assim, para contribuir com informações estratégicas para a defesa sanitária, 1439 amostras foram analisadas quanto à presença de vírus, no período entre 2004 a 2008, sendo $24,2 \%$ provenientes do exterior, pertencentes a 89 gêneros. Dentre as amostras com resultado positivo, 117 estavam infectadas por vírus com morfologia alongado-flexuosa; em 75, foram observadas partículas com morfologia alongado-rígida e em 10 amostras detectaram-se partículas isométricas. As orquídeas corresponderam a 44,2\% do total de amostras examinadas das quais apenas $15 \%$ estavam infectadas. Destaca-se a ocorrência do Alternanthera mosaic virus, espécie exótica ao Brasil.
\end{abstract}

Palavras-chave: inoculação mecânica, ELISA, microscopia eletrônica de transmissão

ABSTRACT

Viruses detected on ornamental plants between 2004 and 2008

The production of ornamental plants has gained growing importance in Brazil. Intending to supply the increasingly exigent internal and external markets led to a gradual boost in this activity. Problems related to cultivation and management of the recently introduced species as well as their sanitation may pose setbacks to Brazilian Floriculture. Aiming to contribute with strategic information concerning ornamental sanitation in Brazil, 1,439 samples were analyzed for virus presence between 2004 and 2008. Among positive samples, 117 were infected with flexuous elongated virus particles, $75 \mathrm{had}$ rigid elongated particles and 10 showed isometric particles. The orchids comprised $44.2 \%$ of the total analyzed samples and only $15 \%$ of them were infected. It is worth mentioning the occurrence of an exotic virus species in Brazil, the Alternanthera mosaic virus.

Keywords: mechanical inoculation, ELISA, transmission electron microscopy

\section{INTRODUÇÃO}

Ao longo das últimas décadas, a floricultura vem apresentando notável desenvolvimento, caracterizando-se como um dos mais promissores segmentos da horticultura intensiva do agronegócio nacional. Apesar da enorme riqueza da flora brasileira, o consumo de flores e plantas ornamentais concentra-se numa reduzida pauta de produtos, muitas vezes importados (ANEFALOS e CAIXETA FILHO, 2007). Algumas razões podem ser citadas como limitantes à expansão da floricultura brasileira, entre elas: escassez de conhecimento das plantas ornamentais em geral, baixa qualidade das sementes e mudas comercializadas, desinformação quanto às condições de cultivo intensivo das espécies, escassez de variedades adaptadas ao nosso clima, estações pouco definidas, entre outras. Ainda assim, o setor vem crescendo ano a ano como mostram os dados da balança comercial da floricultura brasileira, que em 2007, manteve uma taxa de importação na faixa de $30 \%$ de equivalência com os valores exportados, devidos à aquisição internacional de materiais de propagação como bulbos e mudas, necessários à manutenção e desenvolvimento da atividade no país (JUNQUEIRA e PEETZ, 2008).

A produção brasileira é basicamente assegurada pelo mercado interno, contudo cifras superiores a U\$ 35 milhões em vendas anuais equivalem à exportação para Espanha, Estados Unidos, França, Holanda, Japão e outros tantos países (JUNQUEIRA \& PEETZ, 2007). Portanto, é o consumo interno que sinaliza para as reais potencialidades do sucesso econômico. O processo de comercialização, interna e externa, envolve rígido controle dos aspectos fitossanitários. Dentre os fatores imprescindíveis para a conquista do mercado e atendimento às exigências do consumidor, destaca-se o binômio: qualidade-preço, além da garantia de fornecimento. Devido ao fato de o aumento e desenvolvimento do setor de plantas ornamentais ser relativamente recente no país e à constante introdução de mudas e sementes exóticas, tornam-se fundamentais pesquisas relativas ao levantamento da situação, determinação dos problemas e elaboração de metodologias de manejo para suprir as necessidades e dificuldades na área de sanidade vegetal.

Visando atender a um mercado de flores e plantas

\footnotetext{
(1) Recebido para publicação em 24/11/2009 e aprovado em 19/03/2010.

${ }^{(2)}$ Laboratório de Fitovirologia e Fisiopatologia, Instituto Biológico. Av. Cons. Rodrigues Alves, 1252, São Paulo, SP 04014-002.

${ }^{(3)}$ Lab. de Microscopia Eletrônica, Instituto Biológico.
} 
ornamentais, cada vez mais exigente em relação à qualidade e sanidade, os laboratórios de Fitovirologia e Fisiopatologia (LFF) e de Microscopia Eletrônica, do Centro de Pesquisa e Desenvolvimento de Sanidade Vegetal do Instituto Biológico, vêm desenvolvendo pesquisas e realizando prestação de serviço na área de virologia.

Neste trabalho é apresentado um panorama da situação relativa a vírus, com base em exames realizados a partir de amostras de plantas ornamentais recebidas no período de janeiro de 2004 a dezembro de 2008.

\section{MATERIAL E MÉTODOS}

Foram examinadas 1439 amostras de espécies ornamentais, pertencentes a 89 gêneros, dentre os quais: Abutilon, Adiantum, Agave, Ajuga, Alstroemeria, Alternanthera, Alyssum, Angelonia, Antirrhinum, Anthurium, Argyranthemum, Asclepias, Aster, Bacopa, Beaucarnia, Begonia, Bougainvillea, Calendula, Calibrachoa, Callistephus, Catharanthus, Celosia, Chrysanthemum, Coleus, Crossandra, Cuphea, Cupressus, Cycas, Dahlia, Delphinium, Dianthus, Diascia, Dieffenbachia, Eucharis, Euphorbia, Evolvulus, Fuchsia, Gaura, Gerbera, Gladiolus, Gypsophila, Helianthus, Helichrysum, Heliconia, Hibiscus, Hippeastrum, Hypericum, Hypoestes, Impatiens, Ixora, Lilium, Limonium, Lisianthus, Lobelia, Lonicera, Musa, Nemesia, Osteospermum, Pachystachys, Papaver, Passiflora, Pelargonium, Pentas, Petunia, Phlox, Pinus, Polianthes, Portulaca, Primula, Rhoeo, Ruellia, Salvia, Sanchesia, Scaevola, Scutellaria, Streptosoleni, Tagetes, Torenia, Tradescantia, Tropaeolum, Tulipa, Verbena, Viola, Zamioculcas, Zantedeschia, Zinnia), distribuídos em 56 famílias botânicas, além dos diversos de orquídeas, abóbora ornamental e cactos.

A identificação dos vírus foi realizada por meio de testes biológicos, sorológicos e/ou exame ao microscópio eletrônico de transmissão.

$\mathrm{Na}$ inoculação mecânica, fragmentos de folhas, caules ou pétalas foram triturados em presença de sulfito de sódio $0,5 \%$ ou de tampão fosfato de sódio e potássio $0,01 \mathrm{M}, \mathrm{pH} 7,2$. Os extratos foram friccionados em folhas de espécies indicadoras de Amaranthaceae (Gomphrena globosa), Asteraceae (Zinnia elegans), Balsaminaceae (Impatiens holstii), Chenopodiaceae (Chenopodium amaranticolor, C. quinoa e C. murale), Solanaceae (Datura metel, D. stramonium, Solanum lycopersicon, Nicotiana benthamiana, N. clevelandii, $N$. debneyi, N. glutinosa, N. megalosiphon, N. rustica, N. tabacum 'Samsun', 'White Burley' e Petunia hybrida) e Scropulariaceae (Torenia sp.). As plantas inoculadas mecanicamente foram transferidas para casas de vegetação, livres de insetos, para a observação dos sintomas.

Os testes sorológicos (ELISA-indireto ou DAS-ELISA) foram realizados a partir de extratos de tecidos infectados e sadios (controle negativo), preparados na proporção de $1 \mathrm{~g}$ : $10 \mathrm{~mL}$, conforme protocolo adaptado de DIJKSTRA e DE JAGER (1998). Foram utilizados os antissoros relacionados na tabela 1 .

A visualização da morfologia e das dimensões das partículas virais, em extratos de tecidos sintomáticos ou não, foi realizada por meio da técnica de contraste negativo (MARTELLI e RUSSO, 1984).

\section{RESULTADOS E DISCUSSÃO}

No período de janeiro/2004 a dezembro/2008, foram examinadas 1439 amostras (oriundas do Brasil e de outros países), das quais $348(24,2 \%)$ foram coletadas por fiscais federais do Ministério da Agricultura, Pecuária e Abastecimento (MAPA): 282 da Holanda, 32 dos EUA, 17 do Japão, seis da Dinamarca, cinco da Tailândia, quatro de Honduras, uma da Costa Rica e uma do Chile. Segundo dados do LFF, desde 1993, a Holanda continua sendo o principal país exportador de plantas ornamentais para o Brasil (ALEXANDRE et al., 2005a). Os EUA ocupam o $2^{\circ}$ lugar e países da América Central e do Sul aparecem pela primeira vez, no período de 2005 a 2007, relacionados a sementes de Pinus provenientes de Honduras e da Costa Rica e de Helianthus annuus do Chile.

Dentre as ornamentais coletadas por fiscais federais do MAPA, o maior número de amostras pertencia aos gêneros Lilium (164), Tulipa (62), Pinus (31), Hippeastrum (Amaryllis) (12) e diversas espécies de orquídeas (11). A maior diversidade de amostras foi recebida em 2004, incluindo além dos bulbos de Lilium, Tulipa, Hyppeastrum e Gladiolus, plântulas de orquídeas e sementes de Alyssum sp., Antirrhinum majus, Calendula officinalis, Callistephus chinensis, Celosia argentea, C. cristata, Chrysanthemum sp., Dahlia variabilis, Delphinium sp., Dianthus caryophillus, D. barbatus, Gerbera sp., Gypsophila sp., Limonium sp., Papaver sp., Petunia x hybrida, Phlox sp., Portulaca sp., Primula sp., Salvia splendens., Tagetes sp., Viola sp. e Zinnia elegans. Nos anos seguintes, houve uma redução no número de espécies examinadas, especialmente sementes, contudo houve a introdução de sementes de Helianthus annuus e de Lisianthus sp., além de bulbos de calla (Zantedeschia elliotiana) em 2006 e sementes de ciprestes em 2007. A partir de 2006 começaram a chegar sementes e/ou embriões de Pinus provenientes dos EUA, Honduras e Costa Rica. Convém destacar que não foi detectado vírus, por meio de teste biológico/microscopia eletrônica, a partir de sementes.

Das amostras provenientes de diversas regiões do Brasil, as orquídeas corresponderam a 44,2\% (636 amostras) do total de material recebido, sendo que em 85,5\% (546 amostras) não foi detectado vírus. Dentre as amostras infectadas 42\% (38 amostras) corresponderam a infecção pelo Odontoglossum mosaic virus (ORSV); 37\% (33 amostras) pelo Cymbidium mosaic virus (CymMV) e 20\% (18 amostras) apresentavam infecção mista (ORSV + CymMV). Orchid fleck virus (OFV) só foi detectado em uma amostra. Das 11 amostras recebidas do exterior (Japão, EUA e Tailândia), apenas uma proveniente da Tailândia estava infectada pelo CymMV.

CymMV (Potexvirus) e ORSV (Tobamovirus) são os vírus mais importantes em orquídeas cultivadas e mais frequentes, devido ao fato de serem espécies de vírus muito estáveis e facilmente transmitidas por tratos culturais (WISLER et al., 1979; RIVAS et al., 1998). A ocorrência de infecção dupla (ORSV + CymMV) pode levar a sintomas mais drásticos do que a infecção com cada um dos vírus isoladamente. 
No período abrangido neste estudo, houve um aumento de $15 \%$ no número de amostras de orquídeas recebidas em relação aos dados anteriores (1992 a 2003) e um aumento no número de plantas sadias, de 58,5\% para 85,5\% (ALEXANDRE et al., 2005a). Este alto índice de plantas sadias pode ser reflexo da amostragem avaliada, ou seja, a maior parte das amostras era proveniente de laboratórios de micropropagação.

Excluindo-se as orquídeas, das 803 amostras examinadas no período, em $653(81,3 \%)$ não foi detectada a presença de vírus. Em 83 amostras foram detectados vírus com morfologia alongado-flexuosa, das quais oito estavam infectadas pelo Bean yellow mosaic virus (BYMV); em 37, alongado-rígida e em 16, isométricas das quais 13 infectadas por Cucumber mosaic virus (CMV). Ocasionalmente foram detectados Badnavirus em Bougainvillea; Chrysanthemum stem necrosis virus (CSNV) e Groundnut ringspot virus (GRSV) em Chrysanthemum sp.; BYMV em Gladiolus, Hippeastrum e Lilium; CMV em Lilium e Catharanthus; Tobacco streak virus (TSV) em Lisianthus; Alternathera mosaic virus (AltMV) em Portulaca, Torenia, Scutelaria, Angelonia e Salvia splendens, além de uma espécie de Tospovirus não identificada em Tropaeolum (tabela 2).

Dentre as espécies provenientes do exterior, os lírios representaram $47 \%$ do total de amostras examinadas. Verificouse, após a germinação dos bulbos, que 120 estavam isentos de vírus. Quanto aos infectados, em 32 foram visualizadas partículas alongado-flexuosas, em 10 partículas isométricas e em três foi observada infecção mista (CMV + partículas alongado-flexuosas). Uma única amostra apresentando flores com quebra de coloração, proveniente do comércio local, foi submetida à exame verificando-se a presença de partículas alongado-flexuosas.

Diversos vírus já foram descritos infectando lírios: Lily symptomless virus (LSV), Lily virus $X$ (LVX), Lily mottle virus (LMoV), CMV, Tulip breaking virus (TBV), entre outros de menor importância (DERKS, 1995). No Brasil, os dois últimos vírus já foram relatados (FURLANETTO et al., 1996; CATTAI et al., 2000; DUARTE, 2008) além de uma espécie de vírus não identificada com morfologia alongada (DUARTE et al., 1995; SEABRA et al., 1998) e em associação com o CMV (SEABRA et al., 1998). Dentre as amostras infectadas por partículas alongado-flexuosas, cinco foram positivas para o BYMV, vírus relativamente comum em gladíolos e Hippeastrum (ALEXANDRE et al., 2005b).

Outra espécie de Liliaceae de grande interesse econômico, recentemente introduzida no mercado nacional, é a tulipa. Bulbos de 36 variedades importadas da Holanda - maior produtor mundial de tulipas- (BUSCHMAN, 2005) foram postos para germinar, verificando-se que 29 lotes foram negativos para a presença de vírus. Dentre as sete amostras infectadas, duas foram positivas para Tobamovirus; uma para Potexvirus (Tulip virus $X=\mathrm{TVX}$ ); em duas foram observadas partículas virais com morfologia alongado-flexuosa e em duas amostras não foi possível identificar os vírus. A ocorrência pela primeira vez do TVX em tulipas no Brasil foi relatada (RIVAS et al., 2009) e também relatado recentemente, pela primeira vez, na Nova Zelândia, em 2007 (WARD et al., 2008).

Com relação ao Hippeastrum, observou-se $93 \%$ de plantas infectadas por vírus com morfologia alongado-flexuosa, sendo uma amostra infectada pelo BYMV, uma pelo Hippeastrum mosaic virus (HiMV) (DUARTE et al., 2009) e uma por Carlavirus.

Dentre os vírus com morfologia alongado-flexuosa incluem-se os Closteroviridae, Flexiviridae e Potyviridae. No presente caso, possivelmente trata-se de Potyvirus, uma vez que são relatadas diversas espécies, incluindo-se o BYMV, já descrito no Brasil (ALEXANDRE et al., 2005b), HiMV (DUARTE et al., 2009), Amazon lily mosaic virus (espécie tentativa) e Amaryllis potyvirus (espécie não reconhecida pelo ICTV) (RAJ et al., 2009). Cabe ressaltar que alguns potyvirus, entre eles Potato virus Y (PVY), Lettuce mosaic virus (LMV), BYMV e HiMV são de grande importância econômica por causar grandes perdas, exigindo o uso sistemático de medidas de controle (SHUKLA et al., 1994).

Neste levantamento, nenhuma espécie de Tospovirus foi detectada em amarílis, embora o GRSV já tenha sido relatado nessa espécie, no Brasil (DUARTE, 2008).

Considerando-se a alta incidência de vírus em amarílis, trabalhos vêm sendo realizados no Brasil, com resultados promissores, visando à obtenção de plantas livres desse patógeno, utilizando termoterapia associada à cultura in vitro de ápices caulinares (AMARAL et al., 2007).

Pela primeira vez, no Brasil, foi detectado o AltMV, em Torenia sp. (DUARTE et al., 2008). Posteriormente, foi detectado em Angelonia, Helichrysum, Portulaca oleraceae, Scutellaria e Salvia splendens. (ALEXANDRE et al., 2008). Como o vírus só havia sido relatado na Austrália, Estados Unidos e Itália e não é transmitido por sementes, provavelmente deva ter sido introduzido através de material propagativo importado e posteriormente disseminado por propagação vegetativa.

Este trabalho evidencia a importância do exame fitossanitário de plantas produzidas no Brasil e, principalmente, de material importado visando impedir a entrada e/ou o estabelecimento de fitopatógenos e pragas exóticas. A adoção desse procedimento permite a produção de plantas ornamentais com mais qualidade para o comércio interno e aumenta a competitividade do país na produção de mudas e flores para o comércio exterior.

\section{REFERÊNCIAS}

ALEXANDRE, M.A.V.; DUARTE, L.M.L.; RIVAS, E.B. Detecção do Alternanthera mosaic virus (AltMV) em espécies de ornamentais. Tropical Plant Pathology, v.33(Supl.), p. S291, 2008.

ALEXANDRE, M.A.V.; SEABRA, P.V.; RIVAS, E.B.; DUARTE, L.M.L.; GALLETI, S.R. Vírus, viróides e fitoplasmas detectados em plantas ornamentais no período 1992 a 2003. Revista Brasileira de Horticultura Ornamental, v.11, p.49-57, 2005a.

ALEXANDRE, M.A.V.; RIVAS, E.B.; TOZETTO, A.R.P.; DUARTE, L.M.L. Lista comentada sobre a ocorrência natural de vírus em plantas ornamentais no Brasil. 2005b. 55p. 
AMARAL, L.; VEIGA, R.F.A.; TOMBOLATO, A.F.C.; BARBOSA, W.; CONAGINO, A. Conservação "in vitro" de germoplasma indexado de três cultivares de Amarílis (Hippeastrum Herb). Revista Brasileira de Horticultura Ornamental, v.13(2), p.113-120, 2007.

ANEFALOS, L.C.; CAIXETA FILHO, J.V. Avaliação do processo de exportação na cadeia de flores de corte utilizando modelo insumo-produto. Revista Brasileira de Economia, v.61 (2), p.1-21, 2007.

BUSCHMAN, J.C.M. Globalisation - Flower - Flower Bulbs - Bulb Flowers. Acta Horticulturae, v.673, p.27-33, 2005: IX International Symposium on Flower Bulbs.

CATTAI, M.B.; DUARTE, L.M.L.; RIVAS, E.B.; GALLETI, S.R. Detecção de CMV-I em plântulas de lírio. Arquivos do Instituto Biológico, v.67, p.87, 2000.

DERKS, A.F.L.M. Lily. In: LOEBENSTEIN, G.; LAWSON, R.H.; BRUNT, A.A. Virus and virus-like diseases of bulb and flower crops. Chichester, 1995. p. 313-321.

DIJKSTRA, J.; DE JAGER, C.P. Practical Plant Virology - Protocols and exercises. Berlin: Springer, 1998. p. 348-362.

DUARTE, L.M.L. Principais vírus em plantas ornamentais. In: ALEXANDRE, M.A.V.; DUARTE, L.M.L.; CAMPOSFARINHA, A.E.C. Plantas ornamentais: Doenças e Pragas, São Paulo, 2008. v.1, p.51-87.

DUARTE, L.M.L.; ALEXANDRE, M.A.V.; HARAKAVA, R. Identificação molecular do Hippeastrum mosaic virus em Amarílis (Hippeastrum sp.). Tropical Plant Pathology, v.34(Supl.), p.S274, 2009.

DUARTE, L.M.L.; ALEXANDRE, M.A.V.; RIVAS, E.B.; MATOS, M.F.; CHAGAS, C.M. Occurrence of Potyviridae in

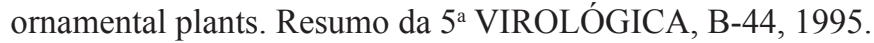

DUARTE, L.M.L. TOSCANO, A.N.; ALEXANDRE, M.A.V.; RIVAS, E.B.; HARAKAVA, R. Identificação e controle do Alternanthera mosaic virus isolado de Torenia sp. (Scrophulariaceae). Revista Brasileira de Horticultura Ornamental, v.14, p.59-66, 2008

FURLANETTO, C.; SILVA, A.M.; TOMITA, C.K.; KITAJIMA, E.W.; RESENDE, R.O. A potyvirus naturally infecting lily plants in Federal District, Brazil. Fitopatologia
Brasileira, v.21 (Supl.), p.431, 1996.

JUNQUEIRA, A.H.; PEETZ, M.S. Exportação de flores e plantas ornamentais superam US\$ 35 milhões em 2007: recorde e novos desafios para o Brasil. http//www.hortica.com.br/ artigos/Balanc_Floricultura_2007.Acesso em 07/01/09

JUNQUEIRA, A.H.; PEETZ, M.S. Mercado Interno para os produtos da floricultura brasileira: características, tendências e importância socioeconômica recente. Revista Brasileira de Horticultura Ornamental. v. 14, p. 43-58, 2008.

MARTELLI, G.P.; RUSSO, M. Use of thin sectioning visualization and identification of plant viruses. Methods in Virology, v.8, p. 143-224, 1984.

RAJ, S.K.; SNEHI, S.K.; KUMAR, S.; KHAN, M.S. First molecular detection and identification of a potyvirus associated with severe mosaic disease of amaryllis (Hippeastrum hybridum Hort.) in India. Australasian Plant Disease Notes, v.4(1), p. 50-53, 2009.

RIVAS, E.B.; ALEXANDRE, M.A.V.; DUARTE, L.M.L. Doenças viróticas. In: BERGMANN, E.C.; ALEXANDRE, M.A.V. Aspectos Fitossanitários das Orquídeas. Boletim Técnico, 1998. n.11, p. 45-51.

RIVAS, E.B.; GALLETI, S.R.; ALEXANDRE, M.A.V.; DUARTE, L.M.L. CHAGAS, C.M. Interceptation of viruses on foreign tulips in Brazil. Arquivos do Instituto Biológico, v.76, p.359-362, 2009.

SEABRA, P.V.; GALLETI, S.R.; RIVAS, E.B.; DUARTE, L.M.L.; ALEXANDRE, M.A.V. Ocorrência de vírus em Lilium sp. Arquivos do Instituto Biológico, v.65 (Supl.), p.57, 1998.

SHUKLA, D.D.; WARD, C.W.; BRUNT, A.A. The Potyviridae. Cambridge, 1994. 516p.

WARD, L.I.; TANG, J.; QUINN, B.D.; MARTIN, E.J.; CLOVER, G.R.C. First report of Tulip virus $X$ in New Zealand. Plant Pathology, v.57(6), p. 1172, 2008

WISLER, G.C.; ZETTLER, F.W.; SHEEHAN, T.J. Relative incidence of Cymbidium mosaic and Odontoglossum ringspot viruses in several genera of wild and cultivated orchids. Proc. Fla. State Hort. Soc. , v.92, p.339-340, 1979. 
Tabela 1. Relação e procedência dos antissoros utilizados

Table 1. List and origin of antibodies

\begin{tabular}{|c|c|}
\hline Antissoros & Procedência \\
\hline Antibodies & Origin \\
\hline Alternanthera mosaic virus (AltMV) & Queensland Horticulture Institute, Austrália \\
\hline Bean yellow mosaic virus (BYMV) & EMBRAPA Soja, Londrina, PR \\
\hline Chrysanthemum stem necrosis virus (CSNV) & EMBRAPA Hortaliças, Brasília, DF \\
\hline Cucumber mosaic virus (CMV) & $\begin{array}{l}\text { Lab. de Fitovirologia e Fisiopatologia (LFF), Instituto Biol ógico (IB), São } \\
\text { Paulo, SP }\end{array}$ \\
\hline Cymbidium mosaic virus (CymMV) & AGDIA, USA \\
\hline Cymbidium ringspot virus (CymRSV) & AGDIA, USA \\
\hline Dasheen mosaic virus (DsMV) & University of Minnesota, Florida, USA \\
\hline Groundnut ringspot virus (GRSV) & EMBRAPA Hortaliças, Brasília, DF \\
\hline Odontoglossum ringspot virus (ORSV) & AGDIA, USA e EMBRAPA Hortaliças, Brasília, DF \\
\hline Passion fruit woodness virus (PWV) & Lab. de Microscopia Eletrônica, Instituto Biológico, São Paulo, SP \\
\hline Tobacco mosaic virus (ToMV) & LFF, IB, São Paulo, SP \\
\hline Tobacco streak virus (TSV) & AGDIA, USA \\
\hline Tomato mosaic virus (TMV) & LFF, IB, São Paulo, SP \\
\hline
\end{tabular}


Tabela 2. Lista das amostras infectadas Table 2. List of infected samples

\begin{tabular}{|c|c|c|}
\hline $\begin{array}{c}\text { Morfologia da partícula } \\
\text { viral }\end{array}$ & Vírus* & Espécies ornamentais \\
\hline Virus particle morphology & Virus & Ornamental species \\
\hline \multirow[t]{6}{*}{ alongado-flexuosa } & $?$ & $\begin{array}{c}\text { Agave, Angelonia, Asclepias, Alstroemeria Begonia, Cactos, Eucharis, } \\
\text { Gladiolus, Helichrysum, Hippeastrum, Impatiens, Lilium, Salvia splendens, } \\
\text { Passiflora gardneri, Verbena, Zamioculcas }\end{array}$ \\
\hline & BYMV & Gladiolus, Hippeastrum, Lilium \\
\hline & AltMV & Angelonia, Helichrysum, Portulaca, Salvia splendens, Scutellaria, Torenia \\
\hline & TVX & Tulipa \\
\hline & CymMV & Orquídeas \\
\hline & DsMV & Dieffenbachia \\
\hline \multirow[t]{3}{*}{ alongado-rígida } & TMV & Tulipa \\
\hline & ORSV & Orquídeas \\
\hline & Tobamovirus & Cactos, Calibrachoa, Impatiens, Petunia, Rhoeo, Torenia, Verbena \\
\hline \multirow[t]{3}{*}{ isométrica } & $?$ & Beaucarnia recurvata \\
\hline & CMV & Catharanthus, Lilium \\
\hline & TSV & Lisianthus \\
\hline $\begin{array}{c}\text { isométrica (partículas cheias } \\
\text { e vazias) }\end{array}$ & $?$ & Diascia \\
\hline \multirow[t]{2}{*}{ baciliforme } & ? Badnavirus & Bougainvillea \\
\hline & OFV & Orquídea \\
\hline \multirow[t]{3}{*}{ pleiom órfica } & ? Tospovirus & Tropaeolum \\
\hline & $\mathrm{CSNV}$ & Chrysanthemum \\
\hline & GRSV & Chrysanthemum \\
\hline
\end{tabular}

* Alternanthera mosaic virus (AltMV), Bean yellow mosaic virus (BYMV), Cucumber mosaic virus (CMV), Chrysanthemum stem necrosis virus (CNSV), Cymbidium mosaic virus (CymMV), Dasheen mosaic virus (DsMV), Groundnut ringspot virus (GRSV), Orchid fleck virus (OFV), Tobacco mosaic virus (TMV), Tobacco streak virus (TSV).

$?=$ Espécie viral não identificada/ non identified virus species 